\title{
Streptomycin and INAH in the Treatment of Leprosy
}

\section{A Preliminery Communication}

\author{
A. B. A. KARAT, B.Sc., M.B.B.S., M.R.C.P.(LOND.), M.R.C.P.(EDIN.) \\ Consultant Physician, Schieffelin Leprosy Research Sanatorium, B.O., Karigiri, \\ via Katpadi, N.A. Dist., S. India \\ P. S. S. RAO, M.A., M.P.H., F.S.S. \\ Lecturer in Bio-statistics, Christian Medical College and Hospital, Vellore, N.A. Dist., S. India \\ Mrs. S. KARAT, M.B.B.s., F.R.c.s. \\ Consultant Surgeon \\ C. K. JOB, B.SC., M.D., M.C. PATH. \\ Consultant Pathologist, Schieffelin Leprosy Research Sanatorium, B.O., Karigiri, \\ via Katpadi, N.A. Dist., S. India
}

Since the introduction of DDS (DiamenoDiphenyl Sulphone) in $1941^{1}$ as a specific treatment for the various types of leprosy, there has been a revolution in the thinking of physicians engaged in the treatment of leprosy. DDS brought new hope and offered, for the first time, definite possibility of cure for the leprosy patient. However, the initial therapeutic enthusiasm has gradually begun to wane with the realisation that DDS is no longer the 'wonder drug' it was hoped it would be. The main limitations of DDS are the slow clearance of bacilli ${ }^{2}$ and hence the need for prolonged treatment; and the tendency of DDS to produce progressive neurological deficit and to precipitate reactive phases of the disease in all types of leprosy except the indeterminate group. ${ }^{345}$ Hence the search for a new drug that is likely to be able to clear the bacilli quickly and at the same time be free of sideeffects continues. To date no such drug is available.

Davison $^{6}$ reported on a limited trial of Streptomycin and INAH in lepromatous leprosy and found the improvement on bi-weekly treatment with this combination comparable to that on DDS in relation to lepromatous infiltrations and nodules. Dreisbach and Cochrane? conducted a trial of the combination of streptomycin and INAH (Isonicotinic acid hydrazide) in leprosy and concluded that this had a limited value in the management of leprosy except in patients with mucosal involvement (nose and larynx). We have been attracted to the use of streptomycin and INAH in leprosy both because this combination effectively combats infection by another mycobacterium, and because of the relatively short time taken for 'sputum conversion' to occur even in patients with fairly advanced pulmonary tuberculosis. We were also struck by the rapid improvement in clinical and bacteriological status of patients with lepromatous leprosy and tuberculosis when they were treated with a combination of daily injections of $1 \mathrm{~g}$. of streptomycin along with $300 \mathrm{mg}$. of INAH orally. This prompted us to undertake a prospective study of the use of combination of streptomycin and INAH in various types of lepromatous leprosy. This report is in the form of a preliminary communication.

MATERIAL AND METHODS

Schieffelin Leprosy Research Sanatorium in Karigiri, South India, is situated in an area endemic for leprosy. Being a research institution, leprosy patients with various complications come to this hospital from all over the country. There 
are just over 14,000 patients on the register. Sixteen to $17 \%$ of the patients have lepromatous leprosy. Twenty-five typical lepromatous leprosy patients were included in the trial. The age-sex distribution of the sample studied is shown in Table 1 .

Tabre 1

Sample Studied

\begin{tabular}{cccc}
\hline $\begin{array}{c}\text { Age } \\
\text { (years) }\end{array}$ & Male & Female & Total \\
\hline$<15$ & 4 & - & 4 \\
$>15$ & $15^{*}$ & 6 & $21^{*}$ \\
\hline Total & $19^{*}$ & 6 & $25^{*}$
\end{tabular}

2 patients had 2 courses of treatment with Streptomycin and INAH, making a total of 27 trials.

Patients chosen were those who were intolerant of DIDS and were liable to recurrent attacks of erythema nodosum leprosum (ENL) and/or acute neuritis (acute painful enlargement of nerves). Some patients had advanced lepromatous leprosy, some others had lepromatous laryngitis with hoarseness of voice and some had severe involvement of nasal mucous membrane as judged by complaints of difficulty in breathing due to blocking of the nose, epistaxis and/or collapse of the nasal bridge. Some of the patients had acute lepromatous skin ulceration. Table 2 shows clinical findings at admission to this trial.

TABLE 2

Clinical Findings at Admission to Therapy

Male Female Total

\begin{tabular}{lrrr}
\hline $\begin{array}{l}\text { Erythema Nodosum Leprosum } \\
\text { (ENL) }\end{array}$ & 10 & 3 & 13 \\
ENL with Neuritis & 5 & 1 & 6 \\
ENL with acute ulceration & 1 & - & 1 \\
ENL with Tuberculosis & 3 & - & 3 \\
Neuritis with ulceration & 1 & - & 1 \\
Ulceration & 1 & 2 & 3 \\
\hline Total & 21 & 6 & 27
\end{tabular}

Routine skin smears were taken once a month in most cases according to the slit skin method and read on a 0 to 6 scale of Ridley. ${ }^{8}$ The initial bacteriological index on this scale is indicated in Table 3.

TABLE 3

Bacterial Index at Start of Therapy

\begin{tabular}{cccc}
\hline $\begin{array}{c}\text { Basterial } \\
\text { Index }\end{array}$ & Male & Female & Total \\
\hline $1-$ & 4 & 1 & 5 \\
$2--$ & 4 & 2 & 6 \\
$3-$ & 6 & 1 & 7 \\
$4-$ & 6 & 2 & 8 \\
$5-$ & 1 & - & 1 \\
\hline Total & 21 & 6 & 27 \\
\hline
\end{tabular}

\section{RESPONSE TO TREATMENT}

The change in bacteriological index (B.I.) during the period on treatment with streptomycin and INAH is depicted in Table 4. Of the 27 trials, in 25 there was significant improvement in B.I. In one case there was no change and in another there was an increase of 0.13 from 1.37 to 1.50 .

TABLE 4

\section{Change in Bacterial Index during Streptomycin / INAH Regime}

\begin{tabular}{cccc}
\hline $\begin{array}{c}\text { Decrease in } \\
\text { Bacterial } \\
\text { Index }\end{array}$ & Male & Female & Total \\
\hline$<.5$ & 2 & 1 & \\
$.5-$ & 7 & 2 & 3 \\
$1.0-$ & 2 & 1 & 3 \\
$1.5-$ & 3 & 1 & 4 \\
$2.0-$ & 3 & 1 & 4 \\
$2.5-$ & 1 & - & 1 \\
$3.0-$ & 1 & - & 1 \\
\hline Total & 19 & 6 & 25 \\
\hline
\end{tabular}

In over $90 \%$ of the samples under study, there was a decrease in B.I. There was no noticeable sex difference in the response to treatment.

The change in B.I. in relation to the duration of treatment is shown in Table 5 . 
TAB1.E 5

Change in Bacterial Index according to Duration of Therapy

\begin{tabular}{|c|c|c|c|c|c|c|}
\hline \multicolumn{2}{|c|}{ Duration Months } & & \multicolumn{2}{|c|}{$3-$} & \multicolumn{2}{|c|}{$6--$} \\
\hline \multirow{2}{*}{$\begin{array}{c}\text { Decrease in } \\
\text { Bacterial } \\
\text { Index }\end{array}$} & \multirow[b]{2}{*}{$M$} & \multirow[b]{2}{*}{$F$} & \multicolumn{2}{|c|}{ Sex } & \multirow[b]{2}{*}{$M$} & \multirow[b]{2}{*}{$F$} \\
\hline & & & $M$ & $F$ & & \\
\hline$<.5$ & 1 & & 1 & 1 & & \\
\hline $.5-$ & 1 & & 4 & 1 & 2 & ; \\
\hline $1.0-$ & 1 & 1 & 1 & & & \\
\hline $1.5-$ & 1 & 1 & 2 & & & \\
\hline $2.0-$ & & & 2 & & $!$ & ! \\
\hline $2.5-$ & & & & & 1 & \\
\hline $3.0-$ & 1 & & & & & \\
\hline Total & 5 & 2 & 10 & 2 & 4 & 2 \\
\hline
\end{tabular}

The change in B.I. according to initial pretreatment B.I. is shown in Table 6 .

TABLE 6

Ghange in Bacterial Index according to Initial Bacterial Index

\begin{tabular}{lccccc}
\hline $\begin{array}{c}\text { Decrease in } \\
\text { Bacterial Index }\end{array}$ & $1-$ & \multicolumn{5}{c}{ Initial Bacterial Index } \\
& $2-$ & $3-$ & $4-$ & $5-$ \\
\hline$\times .5$ & 1 & 2 & & & \\
$.5-$ & 3 & 2 & 2 & 2 & 2 \\
$1.0-$ & & 2 & 1 & & \\
$1.5-$ & & 2 & 2 & \\
$2.0-$ & & 1 & 3 & \\
$2.5-$ & & & & 1 & 1 \\
$3.0-$ & 4 & 6 & 6 & 8 & 1 \\
\hline
\end{tabular}

From Tables 5 and 6 it is obvious that the maximum response occurred in this sample between 3 and 6 months. Further, it is seen that the higher the initial B.I., the more rapid and greater is the fall in B.I. (Fig. 1-scatter diagram.)

The patient in whom there was no change in B.I. had hoarseness of voice which improved rather dramatically while on trial. But the treatment had to be stopped at the end of 30 days because of onset of vertigo and unsteadiness of gait. The one patient who showed a small rise in B.I. had chronic eyrthema nodosum which continued during treatment with streptomycin and INAH and hence the treatment was stopped at the end of 2 months.

\section{CLINICAL RESPONSE}

The change in B.I. in relation to clinical findings at initiation of treatment is presented in Table 7 .

It appears as though patients with erythema nodosum leprosum (ENL) show lesser improvement in B.I. compared to those who did not have ENL. The best response is seen in those with lepromatous nodules as well as those with acute leprous skin ulceration. ${ }^{9}$ (Photographs: Figs. 2, $3,4,5$.) In addition, the cosmetic results in these patients are very gratifying. The changes in B.I. in patients with nodules and acute ulceration is emphaised through Table 8 .

TABLE 7

Ghange in Bacterial Index in relation to Clinical Findings at Initiation of Treatment

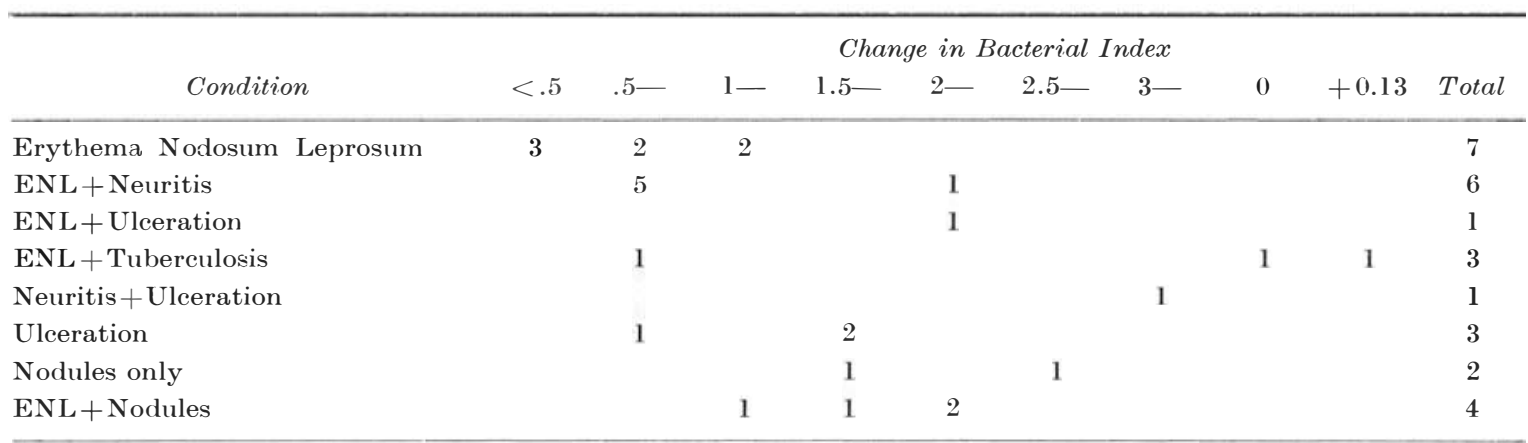




\section{SCATTER DIAGRAM}

SHOWING INITIAL B. I. AND CHANGE IN B. 1. DURING STREP.

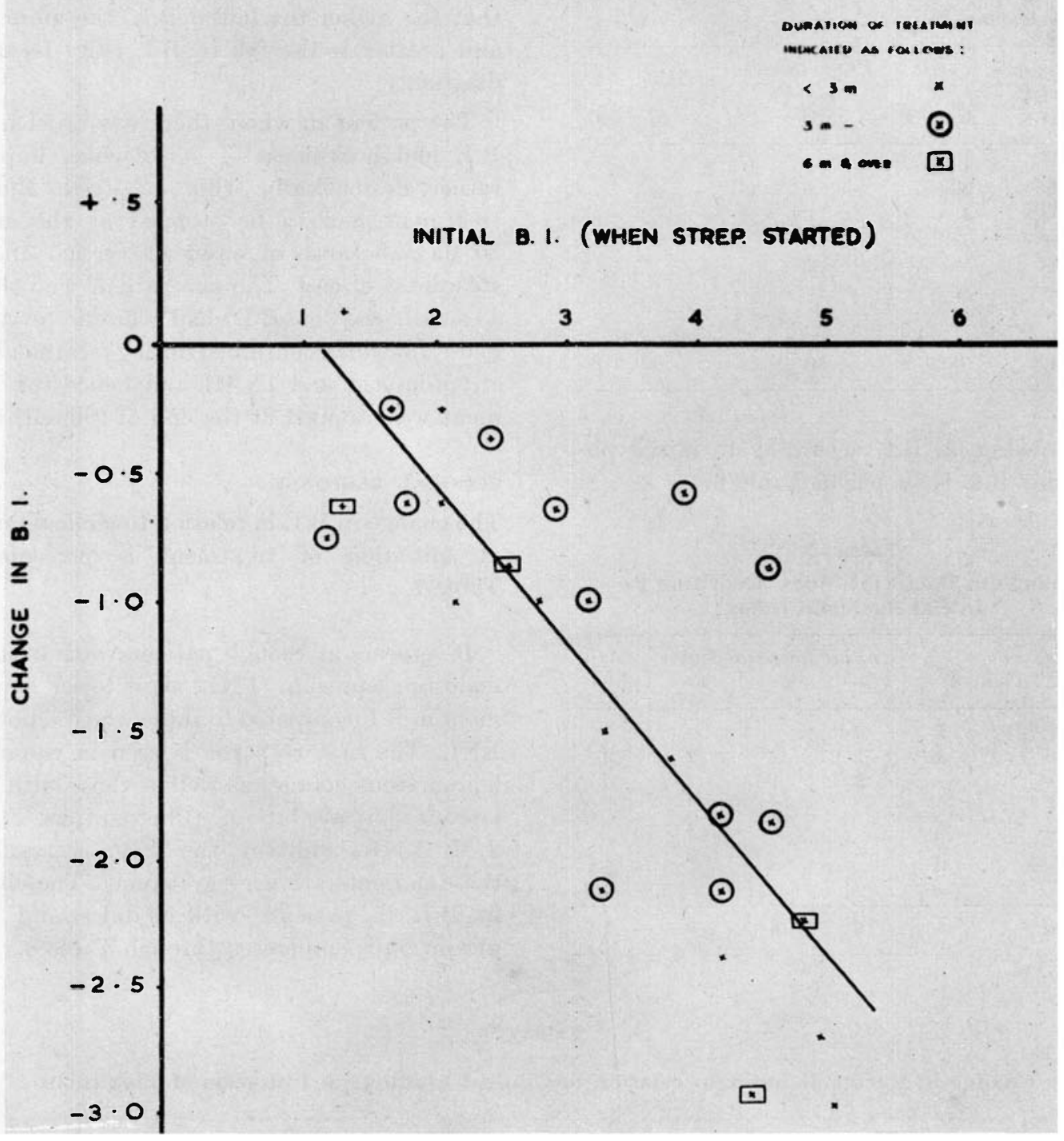

FIG. 1

Scatter diagram showing initial bacterial index and change in bacterial index during treatment with Streptomycin and INAH.

In 3 patients with hoarseness of voice due to lepromatous laryngitis, there was rapid improvement in voice which was noticeable from two weeks of initiation of treatment. Similar dramatic response was seen in another patient with acute lepromatous necrotising lymph- adenitis. ${ }^{10}$ In this patient the septicaemic, swinging temperature came down to normal in a few days, the tenderness and swelling of lymph glands and hepatosplenomegaly cleared up in 2 weeks time.

Of the 25 patients, 21 had erythema nodosum 
TABLE 8

Changes in Bacterial Index in Nodular and Ulcerated Patients

\begin{tabular}{ccc}
\hline Change in Bacterial Index & Nodular & Ulceration \\
\hline$\times .5$ & - & - \\
$.5-$ & - & 1 \\
$1.0-$ & 1 & - \\
$1.5-$ & 2 & 2 \\
$20-$ & 2 & 1 \\
$2.5-$ & 1 & - \\
3.0 & - & 1 \\
\hline Total & 6 & 5 \\
\hline
\end{tabular}

leprosum on admission. All of them gave a history of recurrent episodes of ENL and had become intolerant of DDS on account of recurrent ENL. While on treatment with streptomycin, 4 of these 21 patients developed further crops of ENL. However, except in one of them the ENL episodes were mild, not necessitating interruption of treatment with streptomycin and INAH. In one of them, treatment had to be discontinued at the end of 2 months because of the persistence of fairly severe FNL. It is of interest to note that the rest of the 20 patients were able to tolerate other specific anti-leprosy drugs better at the end of the course of treatment with streptomycin and INAH and are, at the time of reporting, found to be maintaining the progress they had shown while on trial.

Though 7 patients had acute painful peripheral neuritis due to leprosy at admission to the trial, in all of them the peripheral neuritis settled down with relief of pain and no further progression of neurological deficit as judged by sensory charts and the motor assessments of muscles supplied by the affected nerve. This particular result is worth emphasising. While on trial, no patient developed fresh peripheral neuritis and in none was there progression of neurological deficit.

\section{SIDE EFFECTS}

Of the 27 trials in 25 patients, 3 developed disturbance of vestibular function as evidenced by complaints of vertigo and demonstration of unsteadiness of gait and incoordination. In all of them, the symptoms and signs cleared up within a few days of cessation of treatment with streptomycin, the longest duration of vertigo being 3 weeks from cessation of treatment.

\section{DISCUSSION}

The change in B.I. in these patients while they were on non-streptomycin period is depicted in Table 9.

TABLE 9

Change in Bacterial Index during Non-Streptomycin/INAH Regime

\begin{tabular}{|c|c|c|c|c|c|c|}
\hline \multirow{2}{*}{$\begin{array}{c}\text { Change in } \\
\text { Bacterial Index }\end{array}$} & \multicolumn{6}{|c|}{ Duration Months } \\
\hline & $<3$ & $3-$ & $6-$ & $9-$ & $12-$ & Total \\
\hline$<.5$ & - & 3 & - & 1 & 2 & 6 \\
\hline Decrease & - & 3 & 3 & 1 & - & 7 \\
\hline $1-2$ & 1 & 1 & - & - & - & 2 \\
\hline Increased & 22 & 1 & 1 & - & 4 & 28 \\
\hline Total & 23 & 8 & 4 & 2 & 6 & 43 \\
\hline
\end{tabular}

This picture is strikingly different from the one showed for streptomycin and INAH period in Table 5. None showed decrease below 2 units of B.I. despite treatment over one year.

For purposes of comparison of the action of streptomycin and INAH with that of the standard anti-leprosy drug, DDS, a random sample of the charts of 60 lepromatous patients on DDS $600 \mathrm{mg}$ per week (given as $100 \mathrm{mg}$ o.d. for 6 days) was studied in retrospect. The changes in B.I. while on this dose of DIDS is shown in Fig 6 (scatter diagram) in relation to the initial B.I. Comparing this with Fig. 1, which shows the change in B.I. while on streptomycin and INAH, the merits of treatment with the latter are self-evident. While a drop in B.I. of 2 units or more has occurred within 6 months of treatment with streptomycin and INAH in a significant number of patients, similar changes in B.I. while under DDS therapy takes a year or more.

It has long been known that though DDS may kill the bacilli rapidly as judged by the rapid change in morphological index of leprosy 


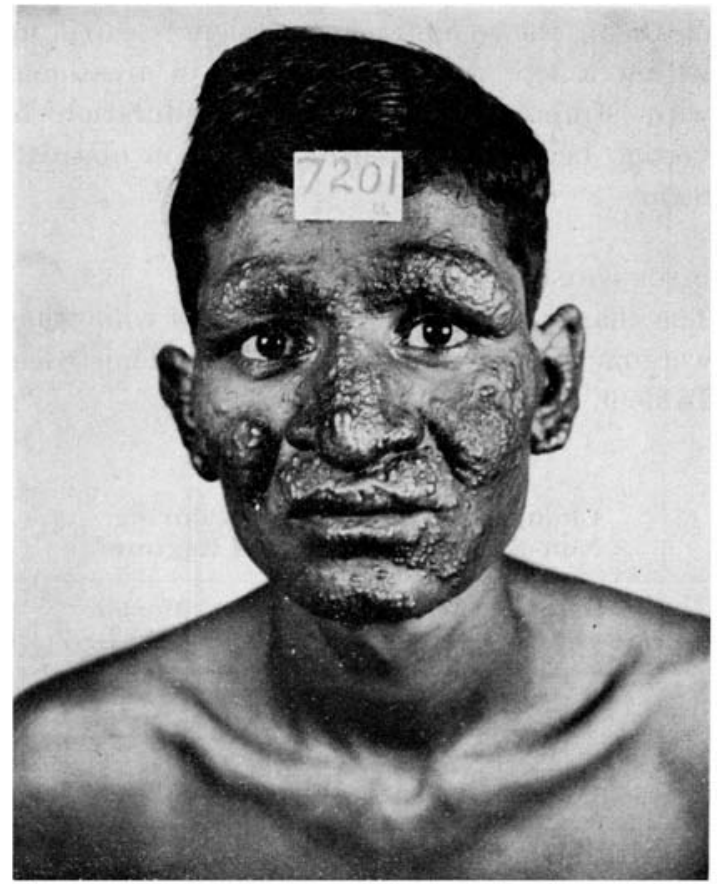

FIG. 2

Nodular lepromatous leprosy before treatment (on 20.8.66).

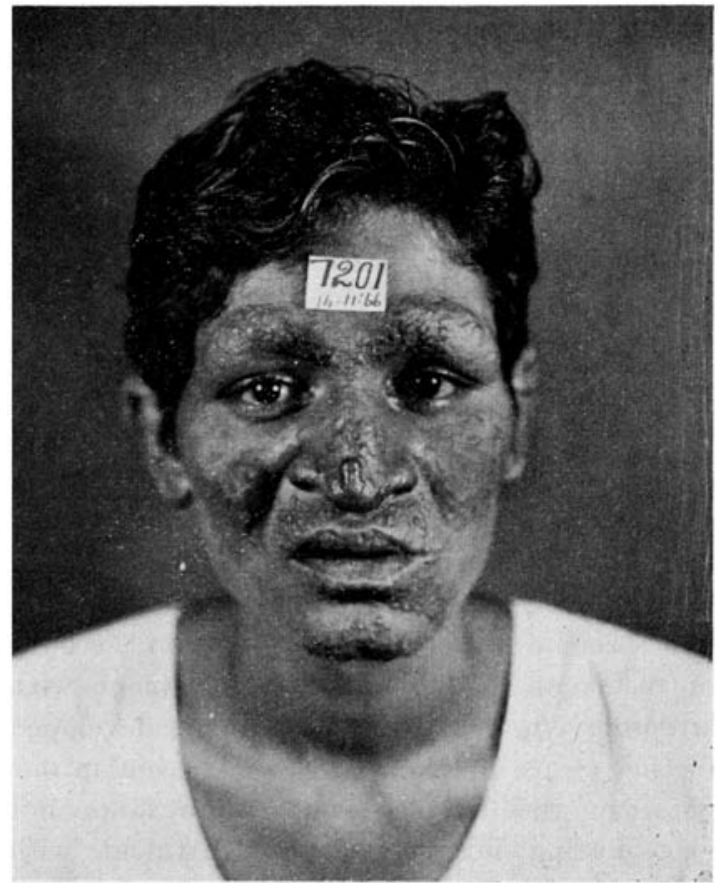

FIG. 3

Same patient as in Fig. 2, after 84 days of treatment with Streptomycin and INAH (on 14.11.66).

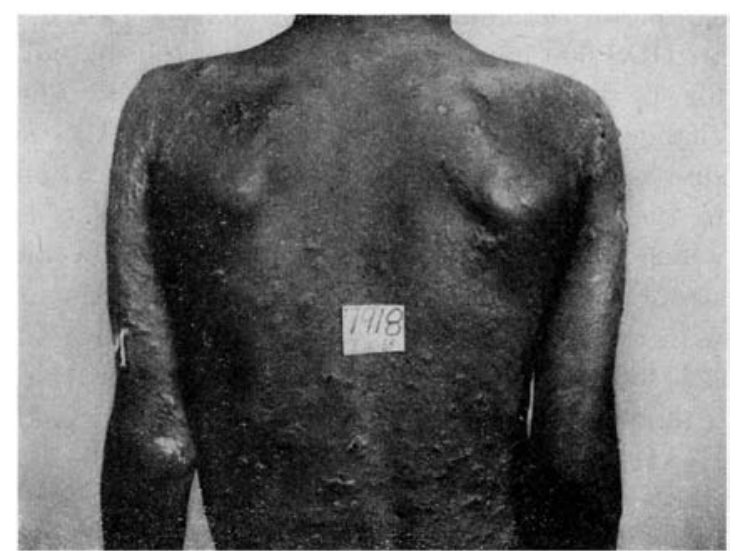

FIG. 4

Showing acute lepromatous skin ulceration before treatment (on 7.12.65)

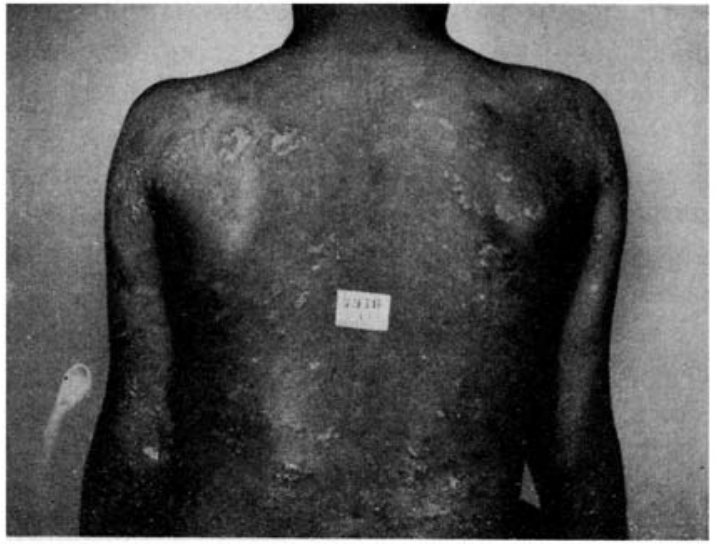

Fig. 5

Same patient (on 6.1.66) 30 days after treatment with Streptomycin and INAH. 


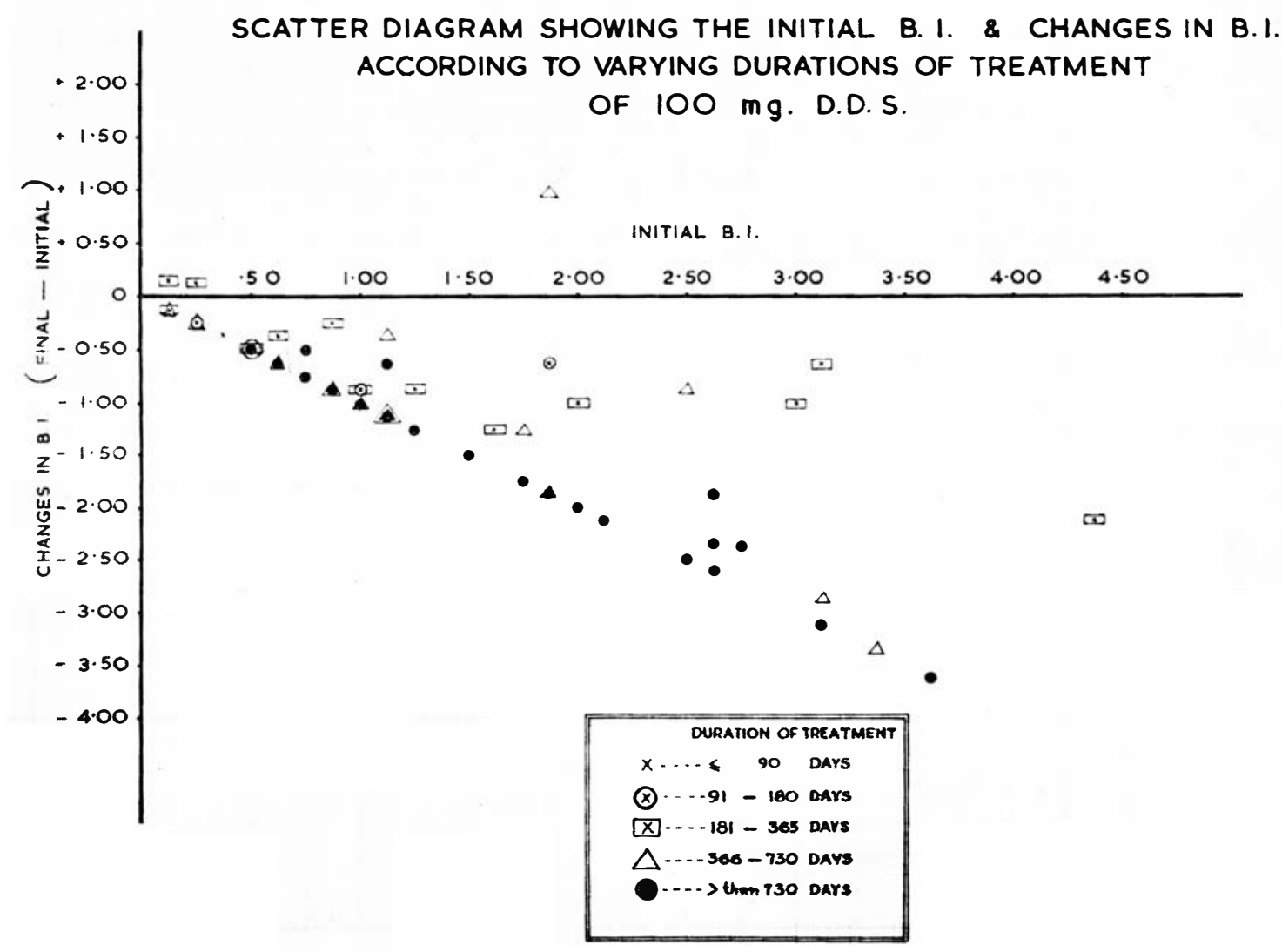

FIG. 6

Scatter diagram showing initial bacterial index and changes in bacterial index according to varying durations of treatment with $100 \mathrm{mg}$ DDS once a day, 6 days a week.

bacilli in patients under DDS therapy, the clinical improvement of the patient does not correspond to the bacteriological index. In other words, the clearance of leprosy bacilli in patients on DDS treatment is a slow process and takes many years. (Personal observation.) This state of affairs is in striking contrast to the effect demonstrated here with streptomycin and INAH. One of the reasons for rapid clearance of bacilli in patients on streptomycin may be the bacteriocidal effect of streptomycin as compared with the bacteriostatic effect of DDS. The mode of disposal of dead leprosy bacilli by the body merits further study. The findings with streptomycin and INAH treatment in leprosy closely parallel those in pulmonary tuberculosis. CONCLUSIONS

From the data presented so far, it appears as though the maximum benefit occurs in those with nodular leprosy and acute leprous ulcers in terms of drop in bacterial index. The improvement in patients with hoarseness of voice, acute leprous lymphadenitis and acute leprous peripheral neuritis are also worthy of note. The reduction in the incidence of ENL and the improved tolerance of anti-leprosy drugs among lepromatous leprosy patients subject to recurrent ENL following a course of treatment with streptomycin and INAH are other useful features. 


\section{SUMMARY}

1. Therapeutic trial of daily intramuscular injection of $1 \mathrm{~g}$. of streptomycin sulphate along with $300 \mathrm{mg}$. of INAH orally in 25 patients with typical lepromatous leprosy is presented.

2. A significant reduction in bacteriological index was noticed in all except 2 patients.

3. Maximum drop in B.I. occurred in those with nodular lepromatous leprosy as well as in those with acute leprous skin ulceration.

4. Significant clinical improvement was noticed in the voice of patients with hoarseness due to lepromatous laryngitis; in acute leprous peripheral neuritis and in acute necrotising lepromatous lymphadenitis.

5. Of 21 patients who on admission had ENL and a history of recurrent ENL, only 4 developed ENL while on trial. In 3, the ENL was mild and in one patient ENL was severe enough for the trial to be suspended.

\section{ACKNOWLEDGEMENTS}

We would like to thank The Leprosy Mission, London, and the American Leprosy Missions, Inc., New York, for continued encouragement and financial support.

We are grateful to Mrs. L. Furness for secretarial assistance; Mr. Christopher Dorairaj and Mr. Sigamoni for photographs; Mr. Chelladurai for clerical assistance.

\section{BIBLIOGRAPHY}

1. FAGEL, G. H., POGGE, R. C., JOHANSEN, F. A., DINAN, J. F., PRAJEAN, B. M. and ECClES, C. G. 'The Promin Treatment of Leprosy: A Progress Report.' Publ. Hlth. Rep., Wash., 65, 1,147, 1943.

2. вUSнву, s. R. м. 'Chemotherapy' in 'Leprosy in Theory and Practice,' 1964. Published by John Wright \& Sons Ltd., Bristol, 354.

3. NOORDEEN, S. K. and SRINIVASAN, H. 'Epidemiology of Disability in Leprosy. 1. A General Study of Disability among Male Leprosy Patients above Fifteen Years of Age.' Int. J. Lepr., 34, 159-169, 1966.

4. SRInivasan, H. and noordeen, S. K. 'Epidemiology of Disability in Leprosy. 2. Factors Associated with Low Disability.' Int. J. Lepr., 34, 170-174, 1966.

5. DAVEY, T. F. 'Newer Drugs in Therapy' in 'Leprosy in Theory and Practice,' 1964. Published by .John Wright \& Sons Ltd., Bristol, 391.

6. DAvison, A. R. 'Clinical Evaluation of Isonicotinic Acid Hydrazide as an Adjunct in the Treatment of Lepromatous Leprosy.' Int. J. Lepr., 24, 393-401, 1956.

7. DRIESBACH, J. and COCHRANe, R. G. 'A Study of the Effect of Streptohydrazid on Lepromatous Leprosy over a Period of about Three Years.' Lep. Rev., 29, 136-142, 1958.

8. RIDLEY, D. S. 'Bacterial Indices' in 'Leprosy in Theory and Practice,' 1964. Published by .John Wright \& Sons Ltd., Bristol, 620.

9. KARAT, A. B. A., JOB, C. K. and KARAT, MRs. s. 'Acute Lepromatous Skin Ulceration.' Lep Rev., $38,1,25-29,1967$.

10. Karat, A. B. A., Karat, Mrs. s. and Job, c. K. 'Acute Necrotising Lepromatous Lymphadenitis.' Awaiting publication. 